\title{
Ascertaining the acid mine drainage potential of a mineral concession in south-western Ghana
}

\author{
G. Ofori-Sarpong, K. Osei, R. K. Amankwah \\ University of Mines and Technology, P O Box 237, Tarkwa, Ghana
}

Email address:

goforisarp@gmail.com (G. Ofori-Sarpong), oseik@yahoo.com (K. Osei), richard.amankwah@gmail.com (R. K. Amankwah)

To cite this article:

G. Ofori-Sarpong, K. Osei, R. K. Amankwah. Ascertaining the Acid Mine Drainage Potential of a Mineral Concession in South-Western Ghana, International Journal of Environmental Monitoring and Analysis. Vol. 1, No. 1, 2013, pp. 34-39.

doi: $10.11648 /$ j.ijema.20130101.15

\begin{abstract}
Acid Mine Drainage (AMD) poses a myriad of problems in communities where mining of sulphide-containing ores takes place. Thus current environmental practice requires that samples be tested for their AMD potential before mining commences. In connection with this, samples from a gold concession in south-western Ghana have been investigated for AMD generation potential using Acid-Base Accounting (ABA) techniques. Mineralogical studies indicated that the ore zones were conglomerate whereas the country rock was quartzite. There were also intrusives of mafic dykes (doleritic). Quartz was the main mineral with composition above $75 \%$, and minor minerals included feldspars, sericite, chlorite, mica and pyrite. Geochemical analysis and ABA showed that $57 \%$ of the samples did not contain sulphide minerals, $38 \%$ had sulphur content of $0.01 \%$, and $4 \%$ had between $0.02-0.03 \%$ sulphur. The paste $\mathrm{pH}$ of 228 samples out of $230(99.1 \%)$ was above 6.0 with an average of 7.5, implying that these are not likely to generate AMD. The Net Neutralising Potential (NNP) values of $3 \%$ of the samples were negative and the ratios of Maximum Neutralisation Potential to Acid Production Potential (NP:AP) were less than 1 confirming the possibility of AMD generation. A proactive strategy was developed to contain the possible environmental hazards of this $3 \%$.
\end{abstract}

Keywords: Acid Mine Drainage, Acid Base Accounting, Neutralisation Potential, Acidity Status

\section{Introduction}

Acid Mine Drainage (AMD) is generated when reactive sulphide minerals such as pyrite are exposed to atmospheric oxygen, water and microbial action $[1,2,3,4]$. AMD from abandoned mines, sulphide-bearing mine tailings and acid mine water pits is a major environmental challenge facing many mining companies all over the world.

The management of AMD may be both reactive and proactive. It may be reactive when the AMD is fully blown before measures are taken to mitigate the effects while in the proactive management strategy, a study is conducted before excavation, and remedial measures taken. Some mitigation techniques include the use of soil and water covers, treatment of the acid waters with sulphate-reducing microbes and $\mathrm{pH}$ modifiers such as lime $\left(\mathrm{Ca}\left(\mathrm{OH}_{2}\right)\right)[1,5]$.

Fundamentally, acid drainage generation is influenced by the mineralogy and morphology of the various rocks under consideration. Thus, a study of the mineralogy and the analysis of the relative percentages of both acidic and basic minerals could be used as a predictive tool. Acid-base ac- counting is a tool used in mine waste management to assess the likely discharge of AMD from a mine. It is used to define the geochemical character of different rocks, which is then utilised to ascertain and predict the likely discharge of acidic waters in ores, mine waste or material generated after major excavations [6].

The south-western part of Ghana is currently the home of 8 active large scale gold mining companies and a manganese mine, all of which are surface operations. Mining activities have been going on in this area for many centuries. Due to the presence of sulphides in the ore bodies, AMD is an environmental challenge, and some mining companies take steps to manage the acidic water from mine pits. To extend the life-of-mine, one gold mining company has embarked on an expansion programme.

The site for this expansion programme (Figure 1) comprises of a series of north-east south-west (NE-SW) trending ridges. The rocks that constitute these ridges belong to the Banket Series of the Tarkwaian System of Ghana [8]. The gold mineralization of the deposit is associated with quartz-pebble conglomerates. Four conglomeratic horizons, separated by quartzite units were consistently identified in 
drill holes.

Due to the already existing problem of AMD in this area, it was necessary to investigate and predict the AMD generation potential of the area to be mined. This is currently a requirement of the Environmental Protection Agency in Ghana [7]. In this study, the rocks in the concession to be mined were subjected to acid-base accounting. The constituents of various ore and rock forming minerals were investigated and minerals with the potential to generate acid were identified and quantified. The acid generating potential was then ascertained.

\section{Experimental Investigations}

\subsection{Sampling, Materials and Materials Preparation}

Twenty-four (24) diamond-drill (DD) boreholes approximately $200 \mathrm{~m}$ apart with depth ranging between $90 \mathrm{~m}$ and $200 \mathrm{~m}$, covering the entire study area were selected for the test work.

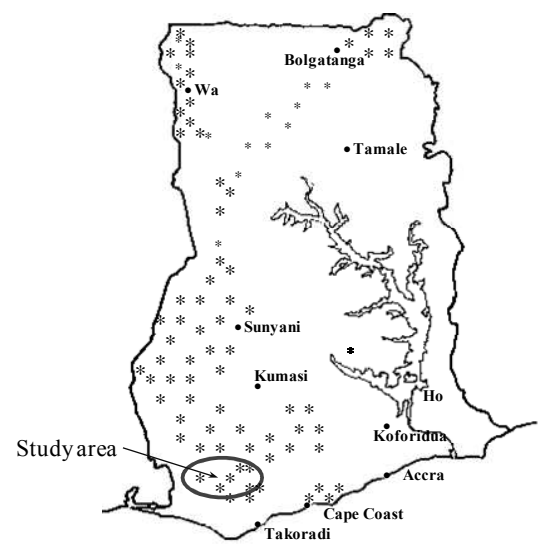

Figure 1. Geological map of Ghana showing the main gold bearing areas and the location of the study area (After Kesse, 1985).

The cores from the boreholes were $63 \mathrm{~mm}$ in diameter, and 230 samples were taken from all identifiable zones (both ore and waste) down the hole. Sample length was generally 20-30 cm.

The core samples were split longitudinally, and one part was used for mineralogical analysis and the other, for chemical analysis. In order to capture all lithologies, various units within the cores were sectioned and analysed. Samples for chemical analysis were crushed and pulverised to $80 \%$ passing $75 \mu \mathrm{m}$ and split using riffles.

\subsection{Mineralogical and Elemental Analysis}

Mineralogical studies were done megascopically and also by thin and polish sections using a Leitz optical microscope under transmitted and reflected light. The various rock forming and ore minerals identified were captured for further studies. Carbon and sulphur were determined by the combustion volumetric technique using LECO SC-144DR Titrator. Carbonates were determined using the hydrochloric acid test while other elements were analysed using the In- ductively Coupled Plasma-Atomic Emission Spectrophotometer (ICP-AES).

\subsection{Acid-base Accounting}

All the 230 samples ( 88 ore and 142 waste rock samples), representing different lithologies, gold grade and degree of weathering were subjected to Acid Base Accounting (ABA) testing. The paste $\mathrm{pH}$ test was performed according to the ABA protocol [9]. The maximum Acid Production Potential (AP) and the maximum Neutralization Potential (NP) were determined according to the guidelines proposed by the United States Environmental Protection Agency [9, 10, 11]. AP was calculated by multiplying the percent sulphide sulphur by 31.25 while NP which is a measure of the carbonate material available to neutralize acid was determined by adding acid to the sample and back titrating to find the amount of acid consumed. The acid/base account or Net Neutralising Potential (NNP) was determined by subtracting AP from NP while Neutralization Potential Ratio was estimated from the ratio of NP and AP.

\section{Results and Discussions}

\subsection{Mineralogical Study}

Examinations of the core samples showed several mineral associations, and these could be grouped into four (4) ore zones, intrusives and waste zones. The ore zones were named 1,2, 3 and 4, and the waste zones were either foot walls or hanging walls. The waste zones were classified as Zone 1 foot wall (Z1-FW), Zone 2 foot wall (Z2-FW), Zones 2 and 3 transition (Z2.3-T), Zone 3 hanging wall (Z3-HW) and Zone 4 hanging wall $(\mathrm{Z} 4-\mathrm{HW})$. Table 1 shows the number of core samples identified in each zone. The ore Zones 1, 2, 3, and 4 were mainly conglomerates though physical parameters such as size, shape and arrangement of grains (texture) varied slightly within the same group.

The photomicrographs in Figures 2a, b and c illustrate the minerals identified in some of the sections examined. Zone 1 samples comprised of weathered feldspars giving rise to sericite and chlorite, porphyritic in places. The matrix consisted of fine grained silica and altered minerals.

The pyrites were equigranular, and tiny rounded crystals of rutile were observed in some samples. Zone 2 minerals were similar to those in Zone 1. However, the pyrites present were mostly euhedral and the subhedral ones had been altered to magnetite and minor amounts of hematite.

Table 1. Number of core samples identified in each zone, arranged in their respective horizons.

\begin{tabular}{ll}
\hline Sample Identification & Number of Cores \\
\hline Zone 4 Hanging wall (Z4-HW) & 23 \\
Intrusives & 3 \\
Zone 4 & 23 \\
Zone 3 Hanging wall (Z3-HW) & 27
\end{tabular}




\begin{tabular}{ll} 
Zone 3 & 24 \\
Zones 2 and 3 transition (Z2.3-T) & 45 \\
Zone 2 & 24 \\
Zone 2 foot wall (Z2-FW) & 26 \\
Zone 1 foot wall (Z1-FW) & 18 \\
Zone 1 & 17 \\
\hline
\end{tabular}

In Zone 3, the quartz grains were sheared and not equigranular. The pyrites were disseminated with some altered to magnetite. Zone 4 had larger subhedral quartz grains and pervasively altered feldspars and micas. Sericites and chlorites, alteration products were also present and imparted a brownish colouration. Pyrite was identified and some of the grains had been transformed into magnetite.

The intrusives were doleritic mafic dykes and contained several quartz grains and feldspars, part of which had weathered into sericite and chlorite. The matrix consisted of fine grained silica and altered minerals. Pyrite particles present were mostly amorphous or deformed, and ilmenite, magnetite and hematite were detected.

The rock type in the hanging and footwalls were quartzite. Most of the feldspars and micas had been altered to sericite and chlorites respectively. Pyrites were disseminated in the section or aligned along fractures. Some of the sulphides had been altered into magnetite. For samples in Z2.3-T, the feldspars were relatively fresh, and not altered.
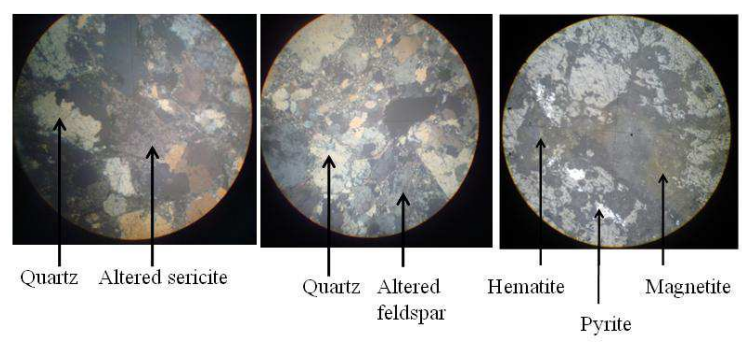

Figure 2. a. Photomicrographs of samples of the intrusives showing quartz, altered sericite and feldspars, pyrites magnetite and hematite.

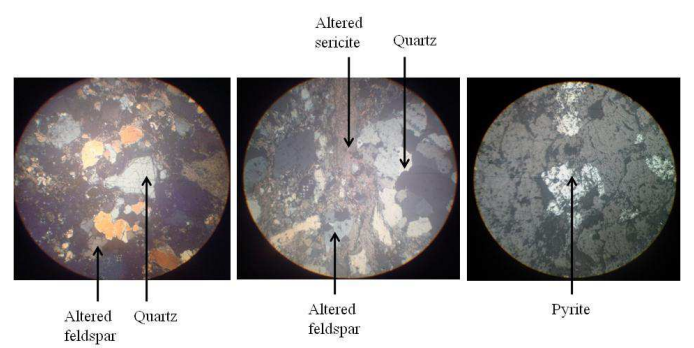

Figure 2. b. Photomicrographs of hanging and footwall samples showing subhedral to euhedral quartz grains and altered feldspars in a matrix of fine grained silica. Also shown are some pyrite grains.

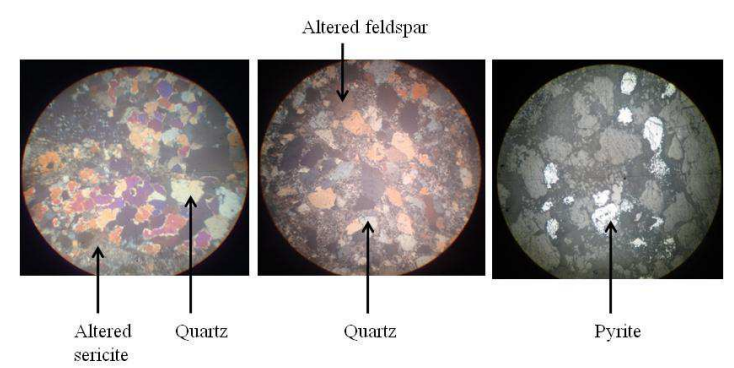

Figure 2. c. Photomicrographs of the ore zone samples showing quartz grains and altered feldspars and sericites. Subhedral and euhedral pyrites are also present.

Mineralogical examination shows that the ore body or Zones 1, 2, 3 and 4 are conglomerate materials while the country rocks (Z1-FW, Z2FW, Z2.3-T, Z3-HW and Z4-HW) which were sedimentary have been metamorphosed to quartzites. The intrusives were mafic dykes (dolerites). Over 75\% of the rocks were composed of quartz. Other minerals included feldspars, biotite, sericites and chlorites. Pyrite was the main mineral constituent that has the potential to generate AMD. The study showed that part of the sulphide minerals had already undergone weathering with the formation of magnetite and hematite. Semi-quantitative mineralogical analysis showed that the pyrite content was less than $0.5 \%$.

\subsection{Acid-Base Accounting}

Acid-base Accounting (ABA) is an analytical technique that generates values to help ascertain the acid-producing and acid-neutralizing potential of rocks, prior to mining and other large-scale excavations. The procedure assists in predicting post-mining water quality and permit-granting decisions $[7,9,12,13]$. To forecast the post-mining water quality, the amount of acid-producing rock is compared with the amount of acid-neutralizing rock, and a prediction of the water quality at the location is deduced.

Geochemical analysis and ABA showed that $57 \%$ of the samples did not contain sulphide minerals and had a maximum Acid Production Potential (AP) of 0.0 tonnes $\mathrm{CaCO} 3$ equivalent per 1000 tonnes of material. About $38 \%$ had a sulphur content of $0.01 \%$ and $4 \%$ between $0.02-0.03 \%$ sulphur. These respectively had AP values of 0.2 and $1.0-$ 0.5 tonnes $\mathrm{CaCO} 3$ equivalent per 1000 tonnes of material. The maximum sulphur content was $0.22 \%$ (Table 2 ) and this is from zone $\mathrm{Z3}-\mathrm{HW}$ with $\mathrm{AP}$ of 6.8 tonnes $\mathrm{CaCO} 3$ equivalent per 1000 tonnes of material. Various researchers agree that sulphur content of $0.5 \%$ and above makes the rock prone to AMD. Thus, with the percentages indicated, the likelihood of AMD generation is low [7, 9, 13].

Paste $\mathrm{pH}$ shows the current acidity status of a sample. In this study, the paste $\mathrm{pH}$ of 228 samples out of 230 (99.1\%) was above 6.0 with an average of 7.5. The remaining two samples had $\mathrm{pH}$ values of 5.0 and 5.2. These were the weathered doleritic intrusives. Paste $\mathrm{pH}$ of rocks that are less than 4.0 is considered acid-toxic $[9,12,13]$. Thus, for this study, no acid-toxic rocks were encountered. It was expected that the oxidation products of the sulphides observed in the 
mineralogical study would impart some amount of acidity to the rocks. Thus, the relatively high $\mathrm{pH}$ values obtained for over $90 \%$ of the samples showed that the acidity was contained by other minerals present.

The Maximum Neutralisation Potential (NP) and Net Neutralising Potential (NNP) generated in Table 2 were plotted against \% sulphide sulphur and presented in Figures $3 \mathrm{a}$ and $3 \mathrm{~b}$ respectively. About $95 \%$ of the samples with sulphide sulphur content less than $0.01 \%$ clustered around the vertical axis as shown in Figure 3a. Seven (7) of the NNP values, representing $3 \%$ of the samples were negative and as shown in Figure $3 b$, such samples are below the zero line. These consist of six (6) country rock samples and one (1) ore sample, and may be classified as having the potential to generate acid.

In ABA studies, samples with NP to AP ratios less that 1 $(<1)$ should produce acid drainage, between 1 and 2 can produce either acid or alkaline water conditions, and $>2$ should produce alkaline water. The results show that $3 \%$ of the samples had NP:AP values less than 1 and these same samples also had negative NNP values suggesting AMD potential. These are from zone Z3-HW. For $57 \%$ of the samples, NP:AP values were undefined as there was no sulphur in the samples, clearly implying that they will not generate AMD. The remaining 40\% had NP:AP values above 2 and thus will not generate AMD [7, 9, 12].

Table 2. Acid-base accounting data for the various zones encountered.

\begin{tabular}{lllllllll}
\hline Zone & \% $\mathbf{C O}_{3}$ & \% S (sulphide) & Paste $\mathbf{p H}$ & AP & NP & NNP & NP/AP \\
\hline Z4-HW & $0.05-3.45$ & $0.00-0.01$ & $6.5-7.8$ & $0.0-0.4$ & $0.1-5.8$ & $-0.1-5.4$ & $\infty-25.1$ \\
Intrusives & $1.45-1.95$ & $0.01-0.02$ & $5.1-5.7$ & $0.3-0.6$ & $2.4-3.3$ & $2.1-2.6$ & $5.2-7.7$ \\
Zone 4 & $0.45-5.55$ & $0.00-0.01$ & $7.2-8.4$ & $0.0-0.3$ & $0.8-9.3$ & $0.8-9.3$ & $\infty-15.6$ \\
Z3-HW & $0.63-7.25$ & $0.00-0.22$ & $6.6-8.0$ & $0.0-6.8$ & $0.1-12.1$ & $-3.1-12.1$ & $\infty-12.3$ \\
Zone 3 & $0.05-8.05$ & $0.00-0.01$ & $7.0-8.1$ & $0.0-0.2$ & $0.1-13.4$ & $-0.9-13.2$ & $\infty-53.8$ \\
Z2.3-T & $0.04-5.25$ & $0.00-0.01$ & $7.2-8.4$ & $0.0-0.3$ & $0.1-8.8$ & $-0.1-8.4$ & $\infty-28.1$ \\
Zone 2 & $0.15-2.05$ & $0.00-0.01$ & $7.1-8.0$ & $0.0-0.3$ & $0.3-3.4$ & $0.0-3.4$ & $\infty-14.4$ \\
Z2-FW & $0.05-9.84$ & $0.00-0.01$ & $7.2-8.2$ & $0.0-0.2$ & $0.1-16.4$ & $-0.2-15.8$ & $\infty-27.2$ \\
Zone 1 & $0.55-3.45$ & $0.00-0.01$ & $6.6-8.3$ & $0.0-0.3$ & $0.8-10.8$ & $0.7-10.2$ & $\infty-18.8$ \\
Z1-FW & $0.55-9.35$ & $0.00-0.01$ & $7.1-8.3$ & $0.0-0.2$ & $0.8-15.6$ & $0.5-15.4$ & $\infty-71.4$ \\
\hline
\end{tabular}

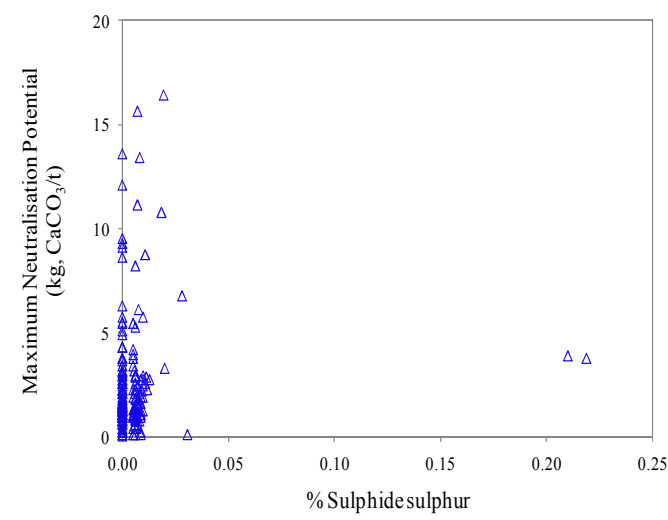

Figure 3. a. A plot of Maximum Neutralising Potential against \% sulphide sulphur.

Though only $3 \%$ showed a potential for AMD generation, it was still necessary to identify them and develop a strategy to contain them. Since the ore sample with the potential for AMD will be leached in a cyanidation circuit at $\mathrm{pH}$ above 10.5 , any acidity will be neutralised by the addition of lime.

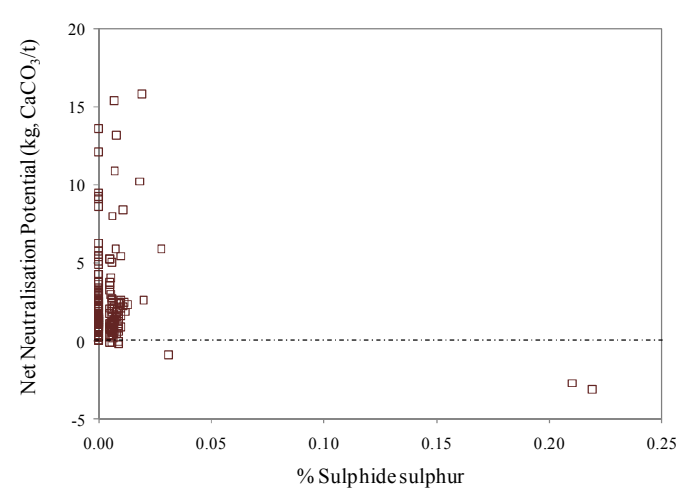

Figure 3. b. A plot of Net Neutralising Potential against \% sulphide sulphur.

After leaching, the waste product will be discharged at a similar $\mathrm{pH}$ and thus enter the tailings impoundment in the neutralised state. By volume, the waste that has the potential to generate acid is low (6 out of 230). Such waste will generate AMD only when exposed and in contact with water, oxygen and chemolithotrophic microbes. These waste materials will be identified during mining and deposited in-between two layers of other materials having no potential for AMD. In this case, the upper layer will serve as a soil 
cover and hence create an anaerobic condition that will not promote AMD.

\subsection{Heavy Metal Ion Concentration}

The results showed the presence of some heavy and toxic metals such as lead, manganese, iron, nickel and cadmium. A few of the samples $(3 \%)$ showed the presence of mercury in the range $0.3-0.2 \mathrm{ppm}$. Ten percent $(10 \%)$ of the samples contained the metalloid arsenic in the range 2-12 ppm. Manganese was present in high concentrations between 100 and $4000 \mathrm{ppm}$ and this could be attributed to the manganese content of the soils as there are minable manganese reserves in that part of Ghana. A graph showing average values of cadmium, lead and nickel in the samples is presented in Figure 4 . The intrusives showed the highest concentrations of lead and cadmium with values of $4.05 \mathrm{ppm}$ and $7.5 \mathrm{ppm}$ respectively. All other samples were below $0.7 \mathrm{ppm}$ cadmium and $5.0 \mathrm{ppm}$ lead whereas nickel concentrations were between 3 and 10 ppm.

These metal ions can be harmful when they are solubilised and become bioavailable. However, the metals can only go into solution when there is acid generation. Based on the ABA studies, there is a very little possibility of acid generation and thus the metals will remain in the minerals and will not be bioavailable.

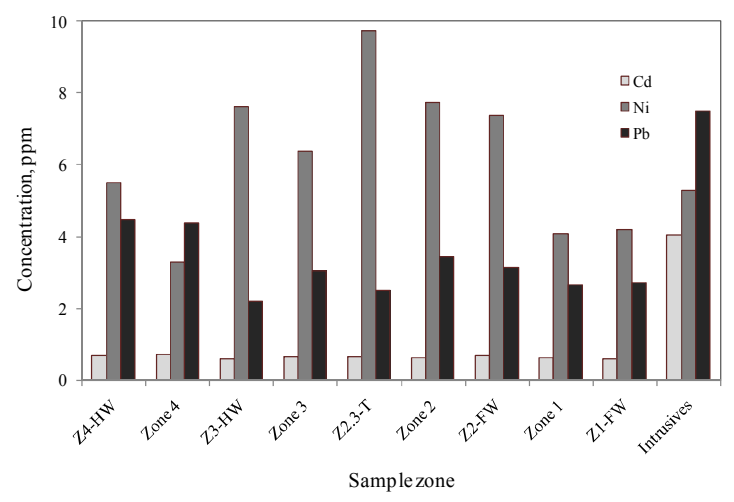

Figure 7. Average concentrations of cadmium, lead and nickel in the various sampling zones.

\section{Conclusions}

Two hundred and thirty (230) samples from a mineral concession in south-western Ghana have been investigated for mineralogical composition and AMD generation potential. The main horizons determined from the drill holes were conglomerate ore zones, quartzite country rock and intrusives of doleritic mafic dykes. The main mineral was quartz with composition above $75 \%$, and others included feldspars, sericite, chlorite and micas. Pyrite was also present in concentrations below $0.5 \%$.

Geochemical analysis and Acid-base Accounting (ABA) showed that $57 \%$ of the samples did not contain sulphide minerals. About $38 \%$ had a sulphur content of $0.01 \%$, and $4 \%$ had $0.02-0.03 \%$ sulphur. The maximum sulphur content was $0.22 \%$ and this was from the Zone 3 hanging wall
(Z3-HW).

The paste $\mathrm{pH}$ of over $95 \%$ of the samples was above 6.0 with an average of 7.5 , whereas the weathered intrusives which formed about $1 \%$ had $\mathrm{pH}$ values of 5.0 to 5.2. Fifty seven percent $(57 \%)$ of the samples had no sulphide sulphur, clearly indicating that they will not generate AMD. About $40 \%$ had NP:AP values above 2 implying they will not generate AMD. Three percent $(3 \%)$ of the samples had negative NNP values, and may be classified as potentially acid-generating. The 3\% also had NP:AP values less than 1 confirming AMD potential.

Based on the study, mining can be allowed though the 3\% material with AMD potential should be managed. Ores with AMD potential will be leached in a cyanidation circuit at $\mathrm{pH}$ above 10.5 and thus any acidity will be neutralized. Such material, if waste, will be identified during mining and sandwiched between layers of material with no acid generation potential during deposition. The upper layer will serve as a soil cover and create an anaerobic condition that will not promote AMD.

\section{References}

[1] Johnson, D. B. and Hallberg, K. B. (2005). Acid Mine Drainage Remediation Options: A Review. Science of the Total Environment, 338(1-2), pp. 3-14.

[2] Kleinmann, R. L. P. (Ed) (2000). Prediction of Water Quality at Surface Coal Mines. The National Mine Land Reclamation Center, West Virginia University, Morgantown, WV, 241 pp.

[3] Akcil, A. and Koldas, S. (2006). Acid Mine Drainage (AMD): causes, treatment and case studies. Journal of Cleaner Production, 14(12-13), pp. 1139-1145.

[4] Tabak, H. H., Scharp, R., Burckle, J., Kawahara, F. K. and Govind, R. (2003). Advances in Biotreatment of Acid Mine Drainage and Biorecovery of Metals: 1. Metal Precipitation for Recovery and Recycle, Biodegradation 14, pp. 423-436.

[5] Yanful, E. K., Simms, P. H. and Payant, S. C. (1999). Soil Covers for Controlling Acid Generation in Mine Tailings: A Laboratory Evaluation of the Physics and Geochemistry. Water, Air, and Soil Pollution 114, pp. 347-375.

[6] Anon (2002). ARD Test Handbook, Environmental Geochemistry International Pty Ltd and Amira International Ltd, Ian Wark Research Institute. Project P387A - Prediction and Kinetic Control of Acid Mine Drainage, pp. A1-G2.

[7] Anon (1994a). Ghana Mining and Environmental Guidelines, Minerals Commission and Environmental Protection Council, Accra, Ghana, 41 pp.

[8] Kesse, G. O. (1985). The Minerals and Rock Resources of Ghana, Balkema, Rotterdam, Netherlands, 610 pp.

[9] Sobek, A., W. Schuller, J. R. Freeman, and Smith, R. M. (1978). Field and Laboratory Methods Applicable to Overburdens and Minesoils. Prepared for U.S. Environmental Protection Agency, Cincinnati, Ohio. EPA-600/2-78-054, $203 \mathrm{p}$.

[10] Ferguson, K. D. and Morin, K. A. (1991). The Prediction of Acid Rock Drainage - Lessons from the Database. Pro- 
ceedings of the Second International Conference on the $\mathrm{Ab}$ atement of Acidic Drainage, Montreal, Quebec, September 16-18, Volume 3, p. 85-106.

[11] Anon (1994b). Acid Mine Drainage Prediction. US Environmental Protection Agency, Self Published, 48 pp.
[12] Brady, K. B. C. and Hornberger, R. H. (1990). The Prediction of Mine Drainage Quality in Pennsylvania. Water Pollution Control Association Pa. Magazine, v. 23, No. 5, pp. 8-15.

[13] Lapakko, K. (2002). Metal Mine Rock and Waste Characterisation Tools: An Overview, Minerals Metals and Sustainable Development, No. 67, 31 pp. 